\title{
Paracetamol induced erythema multiforme major: a rare case report
}

\author{
Mukesh Kumar ${ }^{1}$, Soni $^{2 *}$
}

\author{
${ }^{1}$ Department of Pharmacology, AIIMS, Patna, Bihar, India \\ ${ }^{2}$ Department of Pharmacology, Manipal Tata Medical College, Jamshedpur, Jharkhand, India
}

Received: 09 December 2020

Accepted: 11 January 2021

\section{*Correspondence:}

Dr. Soni,

Email: dr.soni.rmch@gmail.com

Copyright: ( $\odot$ the author(s), publisher and licensee Medip Academy. This is an open-access article distributed under the terms of the Creative Commons Attribution Non-Commercial License, which permits unrestricted non-commercial use, distribution, and reproduction in any medium, provided the original work is properly cited.

\begin{abstract}
Paracetamol is the most quotidian drug used for fever and pain. Adverse drug reaction to paracetamol in India are rare, at times they can lead to lethal situations like erythema multiforme. The most common drug induced erythema multiforme are due to drugs like barbiturate, NSAIDs, penicillin, sulfonamide, nitrofurantoin, phenothiazines and anticonvulsants. There are very few detailed case reports of erythema multiforme due to use of paracetamol. We report a case of erythema multiforme which occurred due to use of paracetamol. The clinical feature and management of patient are described in brief.
\end{abstract}

Keywords: Paracetamol, Erythema multiforme, Adverse drug reaction

\section{INTRODUCTION}

Erythema multiforme major is a form of severe cutaneous reaction following infection or exposure to drug. Commonly implicated drugs are antibiotics, antitubercular and anticonvulsants. Although exact mechanism of the disease is unknown, immune mediated delayed type of hypersensitivity reaction is often implicated in pathogenesis. Paracetamol is a commonly used antipyretic agent and often available as over the counter medication in Indian market. Here we are reporting a rare case of paracetamol induced erythema multiforme.

\section{CASE REPORT}

A 64 years old lady weighing $40 \mathrm{~kg}$, from Giridih, Jharkhand was reported with intensely itchy erythematous vesico-bullous lesions involving forehead, both upper limbs and lower limbs along with ulceration of the tongue. She was admitted in tertiary care hospital, Ranchi. Past history revealed intake of 5 tablets of paracetamol $500 \mathrm{mg}$ thrice daily given by local pharmacist for the complain of fever and malaise. After 3 days of drug in take she developed itchy, erythematous bullous eruptions on her forehead, and. By next two days the lesions enlarged rapidly, coalesced together with central crusting and peripheral erythematous halo. The distribution of lesions was symmetrical in the limbs. The lesions were edematous and blistering. A diagnosis of erythema multiforme major was made clinically and tab paracetamol was suspected to be the offending agent. Re-challenge was not done due to ethical issues. Skin biopsy could not be performed as patient didn't give consent. Laboratory investigations including hematology, biochemistry, serology and urinalysis were within normal limits. Management was stated with injection ceftriaxone $1 \mathrm{gm}$ IV $\mathrm{BD}$, injection pantoprazole $40 \mathrm{mg}$ IV BD, injection Avil IV BD. Silver sulfasalazine cream was prescribed for cutaneous application along with hexedine for mouth wash, Mucopain gel for local application in mouth. Intravenous medications were changed to oral medication after 5 days when the lesions started to heal. After 12 days she was discharged with only topical medications with markedly improved lesions. Two weeks later when she turned up in the dermatology OPD for follow up her lesions were completely healed. Apart from hyperpigmentation of the affected areas there were no other sequalae. 


\section{DISCUSSION}

Erythema multiforme: It is an immune mediated condition affecting the superficial microvasculature of skin and mucous membrane following an infection or drug exposure. The condition varies from a mild, self-limited rash to a severe, life-threatening form. Actually, the term erythema multiforme incorporate spectrum of four disease conditions with similar pathophysiological basis but of varying severity. ${ }^{1}$

Erythema multiforme minor: Acute self-limiting condition with few target lesions or raised, erythematous papules of varying size distributed acrally.

Erythema multiforme major: Multiple, raised, edematous papules ('target lesion'-a dusky red center, a paler halo around this, and a dark erythematous ring around the edge) distributed acrally with involvement of one or more mucous membranes; epidermal detachment involves less than $10 \%$.

Stevens-Johnson syndrome: Widespread blisters predominant on the trunk and face, presenting with erythematous or pruritic macules and one or more mucous membrane erosions; epidermal detachment is $10-30 \%$ total body surface area.

Toxic epidermal necrolysis (TEN): Also known as Lyell's syndrome-a life threatening condition associated with dermo epidermal detachment, involving $>30 \%$ of total body surface area leaving the body susceptible to severe infection.

Erythema multiforme major, SJS and TEN falls under severe progressive disease spectrum of severe cutaneous reaction. Offending agent may be bacterial, fungal, parasitic or viral infection or may be drugs like antibiotics (penicillin, sulfonamides etc.), antitubercular drugs, anticonvulsants (e.g., barbiturates, phenytoin etc.), aspirin and allopurinol etc. ${ }^{2}$

Exact pathophysiology of the disease remains unclear but an immune mediated insult of varying severity is sometimes implicated. The disorder may start with damage to the blood vessels of the skin, which is followed by damage to skin tissues. ${ }^{3}$

Condition usually starts with a prodrome of constitutional symptoms of generalized weakness, fever, joint aches and itching following exposure to the offending agent. Multiple skin lesions developed shortly after the prodromal phase, which may spread over the body. The upper body parts, legs, arms, palms, hands, or feet are involved. Sometimes there is involvement of face or lips. Involvement is usually symmetrical. Lesions may appear as a nodule, papule, or macule and may look like hives. Typically have a central sore surrounded by pale red rings, also called a "target", "iris", or "bulls-eye" lesions. Rapidly turns into vesicles and blisters of various sizes (bullae).
There may be associated redness and drying of eyes with pain, burning, itching, and discharge, blurred vision and mouth sores. ${ }^{4}$

Diagnosis is usually clinical, may be confirmed by tissue biopsy. Histology of the lesion shows characteristic confluent epidermal necrosis with associated inflammation. Basket weave-like pattern of the stratum corneum is seen. The death of keratinocytes causes separation of the epidermis from the dermis. Wide spread cutaneous and mucosal involvement increases the chance of secondary infections, followed by sepsis and multiorgan failure. ${ }^{4}$

Erythema multiforme major is severe cutaneous reaction requires early diagnosis and prompt treatment. Exposure to the offending agent is avoided first followed by supportive management with antihistaminic, antipyretic and analgesic, emollient and topical anesthetics, antibiotics and corticosteroids. Severe involvement of skin sometimes requires skin grafting. Maintenance of strict hygiene and hydration is very essential. In spite of vigorous management case fatality remain on the higher side. $^{5}$

In our case a systemic approach was followed to find out the causal relationship between occurrence of erythema multiforme and intake of paracetamol. She developed skin lesions within 4 days of intake of paracetamol and there was marked improvement after stoppage of paracetamol. The causality assessment was performed using the Naranjo algorithm where the score was +4 and WHO UMC system is also suggestive of a "possible" association.

\section{CONCLUSION}

Paracetamol is a para-amino phenol derivative, also known as acetaminophen is not commonly categorized under NSAID due to its weak anti-inflammatory action. It is the most commonly used antipyretic agent over the world and generally well tolerated. Erythema multiforme major due to paracetamol is rare in reported literature. Nevertheless, it is important to keep it in mind that such severe adverse drug reaction can occur with its use and physicians must be aware of such occurrence, so that prompt action can be taken.

Proper patient consent and permission from Institutional ethical committee was taken before publishing the case report as poster.

\section{Funding: No funding sources \\ Conflict of interest: None declared \\ Ethical approval: Not required}

\section{REFERENCES}

1. Schneider G, Kachroo S, Jones N, Crean S, Rotella P, Avetisyan R et al. A systematic review of validated methods for identifying erythema multiforme 
major/minor/not otherwise specified, StevensJohnson Syndrome, or toxic epidermal necrolysis using administrative and claims data. Pharmacoepidemiology Drug Safety. 2012;21:236-9.

2. Mamatha K, Ravali TR, Chiranjeevi P, Maheswari E. A Case Report on Ciprofloxacin Induced Erythema Multiforme. SAS Tech-Tech J RUAS. 2015;14(2):458.

3. Stevens DL, Bisno AL, Chambers HF, Dellinger EP, Goldstein EJ, Gorbach SL et al. Practice guidelines for the diagnosis and management of skin and soft tissue infections: 2014 update by the Infectious Diseases Society of America. Clinical Infectious Diseases. 2014;59(2):e10-52.
4. Buencamino MC, Goel SS, Tuthill RJ, Taege A. A 19year-old man with oral ulcers, pulmonary infiltrates, and rash. Cleveland Clinic Journal of Medicine. 2007;74(11):773.

5. Farthing P, Bagan JV, Scully C. Number IV erythema multiforme. Oral Diseases. 2005;11(5):261-7.

Cite this article as: Kumar M, Soni. Paracetamol induced erythema multiforme major: a rare case report. Int J Basic Clin Pharmacol 2021;10:198-200. 